\title{
A CONVERGÊNCIA DOS ASPECTOS DE INCLUSÃO DIGITAL: experiência nos domínios de uma universidade ${ }^{1}$ THE CONVERGENCE OF THE ASPECTS OF DIGITAL INCLUSION: experience in the domain of a university
}

\author{
Barbara Coelho Neves - barbaran@ufba.br \\ Mestranda do PPGCI e Pesquisadora (Capes) do GEPEMCI e LABMUNDO \\ Universidade Federal da Bahia - Salvador - BA. \\ Henriette Ferreira Gomes - henriette@ufba.br \\ Doutora em Educação pela FACED-UFBA \\ Professora Adjunta do Departamento de Documentação e Informação e Coordenadora do \\ GEPEMCI da Universidade Federal da Bahia - UFBA.
}

\begin{abstract}
Resumo
Este artigo traz resultados de um estudo de caso, aplicado com técnicas de survey, visando analisar os aspectos da inclusão digital através dos usuários do telecentro Tabuleiro Digital da Faculdade de Educação da Universidade Federal da Bahia - FACED/UFBA. O principal objetivo destinou-se a investigar o tipo de inclusão digital, promovida por este Projeto, em conformidade com a perspectiva da literatura atual. Os objetivos específicos indicam as características do perfil dos usuários; tipos de aplicações utilizadas e a finalidade da Internet em confronto com o nível educacional e social. Desta forma, a sociedade da informação e a inclusão digital são contextualizadas; também os aspectos da inclusão do Tabuleiro são demonstrados e discutidos. Por último, com a análise, foi comprovado que o modelo de inclusão digital do Projeto é induzido (técnico).
\end{abstract}

Palavras-chave: Sociedade da Informação. Inclusão digital. Telecentro.

\section{INTRODUÇÃO}

A Sociedade da Informação, formalizada nos inventos de uma série de máquinas inteligentes criadas ao logo da Segunda Guerra Mundial, origina novas responsabilidades para todos os atores sociais nela inseridos. Tais responsabilidades representam à necessidade da provisão do fluxo de informações que permita desde a geração de novos conhecimentos até o efetivo exercício da cidadania pela sociedade civil.

Varias iniciativas de instituições - mantidas com recursos de origem privada, pública ou mista de mecanismos nacionais e internacionais - têm contribuído com a criação de espaços que proporcionam tipos de acessos variados a informação eletrônica.

A partir das definições de inclusão digital feitas por Lemos e Costa (2005), Sorj (2003), Brasil (2000) e Rondelli (2003), procurou-se verificar a categoria de inclusão digital implementada no ambiente de uma universidade, mais especificamente no telecentro "Tabuleiro Digital" da Faculdade de Educação (FACED) da Universidade Federal da Bahia (UFBA), levando em consideração aspectos ligados ao acesso e perfil do usuário. Para tal achou-se coerente usar como norteadora da pesquisa responder a seguinte pergunta: Como pode ser percebida a

\footnotetext{
${ }^{1}$ A primeira parte desta pesquisa foi apresentada no X Colóquio Internacional sobre Poder Local.
} 
inclusão digital proporcionada por um telecentro nos domínios de uma universidade, precisamente em uma Faculdade de Educação?

A fim de se obter uma visão geral sobre o perfil dos usuários do telecentro e a identificação das variáveis inerentes à inclusão digital, procurou-se seguir a fase exploratória com (pesquisas referenciais e entrevistas com especialistas). Em seguida, gerou-se a pergunta de partida que foi o fio condutor de todo o estudo. Este trabalho, classificado como um estudo de caso teve como unidade-caso o Tabuleiro Digital. O instrumento de coleta de dados foi um questionário.

Este artigo está estruturado em cinco seções. Além desta introdução, na segunda são abordados origens dos espaços de inclusão digital, levando em consideração a experiência brasileira no contexto de inserção na Sociedade da Informação. Em seguida, discorre-se sobre a inclusão digital e o debate mais atual acerca do acesso e de como este influi no resultado final que os programas, desse seguimento, anseiam para o individuo. A quarta parte expõe o caso do Tabuleiro Digital, o recorte metodológico da pesquisa e a discussão dos resultados. Ainda nessa seção, é apresentado detalhadamente o perfil dos usuários, analisando os cruzamentos sob à luz da literatura do tema. Também é possível perceber aspectos e questionamentos ligados ao modelo de acesso utilizado nesse telecentro e o enquadramento em uma categoria específica da matriz utilizada para análise.

Diante do exposto no decorrer do trabalho, a quinta seção apresenta as considerações finais, analisando as necessidades apontadas na pesquisa e a importância de atende-las - observando as objeções e opiniões dos sujeitos do Projeto - em convergência com o que se compreende por inclusão digital.

\section{SOCIEDADE DA INFORMAÇÃO E INCLUSÃO: INÍCIO DE CONVERSA}

A Sociedade da Informação entrou nas referências políticas, econômicas e acadêmicas na década de 60, formalizando-se durante o período da Segunda Guerra Mundial. "A guerra de massa exigia produção em massa" foi o procedimento que "adiantou visivelmente a tecnologia nuclear, aeronáutica e computadores, acelerando o progresso técnico e inovação tecnológica, bases da economia industrial moderna.” (HOBSBAWM, 2005, p. 52-55).

A estrutura social foi configurada para comportar inter-relações entre redes, proporcionando a convergência cultural, política e organizações sociais, visando à exclusão do espaço e anulação do tempo. A Sociedade da Informação adquiriu essa estrutura devido a grandes evoluções ocorridas ao longo da história. E em se tratando de sociedades em sistemas de redes, pode-se afirmar que essa forma organizativa é altamente flexível e dinâmica.

Essas mudanças não aconteceram sem conflitos. Toffler e Toffler (1997) acreditam que a metáfora de "ondas" de mudança é mais dinâmica e reveladora do que falar em transição "pós-moderna”. A mudança econômica estratégica mais profunda é a divisão do mundo em três civilizações distintas e conflitantes:

- A civilização da primeira onda (Agrícola): multidões retiram da terra através da enxada seu sustento, ainda hoje vigente;

- A civilização da segunda onda (Industrial): sociedade de massa em crise; e

Enc. Bibli: R. Eletr. Bibliotecon. Ci. Inf., Florianópolis, n. 26, 2ºm.2008 
- A terceira onda (Informacional): sociedade desmassificada em transição na nova economia, formada por sistemas complexos que requer troca de informações rápidas entre as unidades, maior ou quase nenhuma dependência de países da primeira onda (por ter a informação como substituta da matéria-prima), tecnologia baseada no conhecimento, economia globalizada.

Atualmente, fala-se de uma quarta "vaga" baseada nos avanços da biotecnologia. E assim, na carona das premonições de Alvin Toffler, Maynard; Mehrtens (1999) voltam seus olhares para uma onda revolucionária no campo dos negócios, onde a forma organizativa das empresas sofre transformações quanto ao comportamento e relacionamento com a comunidade, meio ambiente e acumulação de riqueza.

Em muitos países, as três ondas acontecem ao mesmo tempo, sobretudo nos países chamados emergentes, onde ainda há grande parte da população em áreas rurais, forte industrialização e amplo desenvolvimento, além de ações conjuntas de transição da economia, para a "nova era”, baseada no conhecimento como produto.

Para se chegar ao que as tecnologias de informação e comunicação (TIC) representam atualmente, deve-se levar em conta os estágios de inovação em alguns campos da tecnologia: microeletrônica, computadores e telecomunicações.

Em se tratando dos avanços da tecnologia da comunicação, Toffler e Toffler (1997, p.126) afirmam que estas “[...] abrem, pela primeira vez, uma série de possibilidades para a participação direta do cidadão na tomada de decisões políticas”.

Contudo, outras visões não possuem caráter tão positivo em relação à tecnologia, sobretudo, a “[...] Internet, vista como um paradoxo podendo favorecer a globalização ou a nãoglobalização por ser dependente da socioeconômia” (MARSHALL, 2004 p.35, tradução nossa). Dessa forma a "rede das redes" pode ser vista como um elemento tanto de inclusão como de exclusão por sua perspectiva está atrelada ao acesso e participação de grandes setores do mundo contemporâneo.

Na mesma linha, Dijk (2005) concorda que o fenômeno do acesso proporcionado pelas TIC pode ser comparado ao "efeito Matheus". Essa máxima bíblica "[...] for to everyone who, more shall be given” ou "à quem já têm, mais será dado” (Matt. 25:29 apud DIJK, 2005) ilustra como o histórico de segmentos da população interferem no desenvolvimento, baseado em tecnologias, de pessoas, e até mesmo, países.

Mesmo com todos os benefícios que as novas tecnologias de informação têm proporcionado à economia, a participação direta do cidadão na tomada de decisões políticas ainda não atingiu sua forma plena.

Em uma entrevista ao programa Roda Viva (2000) sobre os temas abordados em seu livro A Sociedade em Rede, Castells menciona que:

[...] o principal papel do Estado no lançamento do sistema informacional é equipar a economia do país em tecnologia e recursos humanos para serem capazes de operar nesse novo sistema e organizar essa transição para que os custos sociais sejam os menores possíveis. Hoje, os atores sociais inseridos nessa Sociedade da Informação devem ter uma participação muito mais pró-ativa e facilitadora na difusão dessas novas tecnologias. 
A inserção do Brasil na Sociedade da Informação teve início nas discussões entre o Conselho de Ciência e Tecnologia - CCT e o Instituto Brasileiro de Informação em Ciência e Tecnologia - IBICT contemplando dez objetivos que perpassavam por áreas que vão da Educação às Relações Internacionais. Naquele momento, em 1998 - em um país “[...] subinformado, subeducado e também despreparado para aprender [...]” (CONSELHO..., 1998) - o papel do Governo, nessa fase inicial da Internet, era prover infra-estrutura de informação com velocidade alta, aplicações avançadas, promover experimentos nas áreas das novas TIC e qualidade de serviços (Quality of Service - QoS).

O discurso das frentes envolvidas nos programas que, visavam à difusão da técnica e da Internet, era embasado em um Estado que ocupa uma posição central na relação com o desenvolvimento tecnológico, através de práticas que facilitam as condições para a ampliação dessa tecnologia. E nesse contexto, a educação representa um papel fundamental, visto que se aplicada de maneira eficiente impulsiona o potencial científico e técnico, contribuindo para a geração de riqueza que será revertida na própria educação.

Ainda nesse mesmo contexto, pode-se complementar que “[...] a TIC não é uma variável externa a ser injetada de fora para produzir certos resultados numa realidade existente. Ela deve ser tecida de maneira complexa no sistema social e seus processos." (STAROBINAS, 2006). Não basta apenas a aquisição de computadores com Internet, mas capacitar pessoas que saibam tirar proveito positivo da mesma, constituindo assim, mediadores da informação, multiplicadores, transformando o processo de inclusão na atual sociedade.

\section{DISCUSSÕES SOBRE INCLUSÃO DIGITAL}

O avanço da tecnologia da informação provoca mudanças na maneira dos indivíduos interagirem no meio social (em rede). A informação é um dos fatores decisivos para a globalização (CASTELLS, 1999; MATTELART 2003, SANTOS, 2004) a questão da chamada "digital divide" é um desafio, podendo se constituir em um vetor aos pilares de uma situação favorável aos atores envolvidos no novo sistema mundo. O termo, que traduzido seria algo em torno de "divisória digital”, aparece nas literaturas - sobretudo as de origem norte americanas - a partir de 1990 com o impacto vertiginoso da Internet no mundo (WARSCHAUER, 2006; LEMOS; COSTA, 2005). Em outros idiomas - brecha digital, fissura digital, lacuna digital, fracture numérique - palavras equivalentes foram associadas ao fenômeno que qualifica aqueles que estão à margem da sociedade da informação. Não diferente de outros países, e no Brasil, a expressão "exclusão digital” alimenta um debate fervoroso nas esferas do governo, do terceiro setor e das organizações multilaterais, a exemplo da UNESCO.

A superação dessa desigualdade no acesso tem sido vista como um dos meios de inclusão social, passando a ser considerada como um desafio, já que seria preciso, então, romper com a exclusão digital. Nos primeiros estudos sobre o tema, quando a discussão ainda estava numa fase embrionária, a exclusão digital era, em geral, abordada do ponto de vista estritamente técnico. Afonso (2000), por exemplo, define a exclusão digital como a impossibilidade de se utilizar os recursos das redes públicas de comunicação e informação. Silveira e Cassino (2003), na mesma linha, defendiam que a exclusão digital ocorria ao se privar as pessoas de três instrumentos básicos, o computador, a linha telefônica e o provedor de acesso. 
Atualmente, a discussão é mais avançada e são muito criticadas as definições que abordam a questão do ponto de vista estritamente técnico, por limitar o problema ao acesso físico às ferramentas e ao conteúdo. Tais condições são importantes para a alfabetização digital, mas insuficiente para atender aos requisitos básicos, exigidos em um estágio mais avançado de inclusão, vislumbrado por autores que defendem o letramento digital. Na, então, Sociedade da Informação, tais habilidades são essenciais para a participação plena em processos como a democracia eletrônica e inteligência coletiva, entre outros. A alfabetização digital indica, assim, a aquisição de ferramentas que segundo Bonilla (2001), se constitui em “[...] condição necessária para que aumente o grau de penetração das novas tecnologias na sociedade brasileira, de forma que esta sociedade esteja mais bem preparada para as mudanças em curso.” (BONILLA, 2001, p.1). O letramento digital, por sua vez, merece ser enfatizado por ser "[...] um certo estado ou condição que adquirem os que se apropriam da nova tecnologia digital e exercem práticas de leitura e de escrita na tela [...]” (SOARES, 2002, p.151).

O acesso à informação pela sociedade civil possibilita o desenvolvimento do potencial criativo e intelectual dos indivíduos, além de tornar públicas as proposições políticas e decisões que, tomadas na esfera do Estado, refletem diretamente na qualidade de vida das populações e, de um modo geral, permiti o exercício da cidadania.

Em se tratando de desenvolvimento do individuo, Mattelart (2003, p.71) aborda que a diferença entre conhecimento e informação está somente na lingüística do verbo formar: “informar é uma atividade mediante a qual o conhecimento é transmitido; conhecer é o resultado de ter sido informado".

Diante disso, a maior parte das visões atuais sobre o problema vão além do acesso às ferramentas técnicas e ao conteúdo da Internet, e alguns autores - como Silveira e Cassino (2003) por exemplo - revisam e atualizam essas definições. Silveira (2005) defende que a inclusão digital pode ser entendida a partir de seis dimensões: (1) o acesso à Internet, (2) o acesso aos conteúdos da Internet, (3) o acesso a e-mails (4) o acesso às linguagens básicas e instrumentos para usar a rede, (5) o acesso às técnicas de produção de conteúdo e (6) o acesso à construção de ferramentas e sistemas voltados às comunidades.

Na mesma linha, Sorj (2003), defende que a inclusão digital poderia ser classificada em cinco níveis interdependentes entre si, de forma que para alcançar um nível superior é necessário que o nível anterior tenha sido plenamente satisfeito. A interdependência entre esses cinco níveis é representada graficamente na Figura 2.

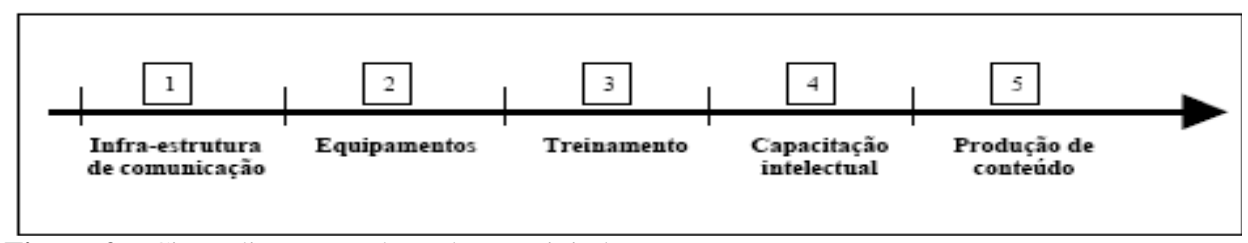

Figura 2 - Cinco dimensões da Inclusão Digital

Fonte: Sorj (2003)

Rondelli (2003), também define quatro passos para a inclusão digital: (1) a oferta de computadores conectados em rede; (2) a criação de oportunidades para que os aprendizados feitos a partir dos suportes técnicos digitais possam ser empregados no cotidiano da vida e do trabalho; (3) a necessidade de políticas públicas e pesquisas que subsidiem as estratégias de inclusão digital; e (4) a exploração do potencial interativo da mídia digital. Ou seja, baseando- 
se em Sorj e em Rondelli, não bastaria a disponibilização do acesso, mas todo um processo complexo que vai desde a indução de maneira educativa (onde a aprendizagem tem papel fundamental) até a exploração máxima dos meios digitais na atual era da informação.

Sobre as conseqüências da exclusão digital, o grande risco, que esta oferece não, é para os países desenvolvidos onde os índices de acesso ao computador e Internet têm crescido exponencialmente nos últimos anos. Para estes países, em pouco tempo essa divisão deve ser superada. Entretanto, para aqueles em desenvolvimento, a oportunidade desigual de acesso às TIC pode reforçar a desigualdade entre indivíduos na mesma região. Outros autores como Eisenberg e Cepik (2002) também defendem que a ambigüidade é ainda mais grave para países em desenvolvimento, onde a assimilação das novas tecnologias coexiste com subdesenvolvimento econômico e acentuada desigualdade social. Para esses países, outras formas de desigualdade já existentes seriam aprofundadas por essa nova forma de exclusão. Mesmo estando em países pobres, cidadãos privilegiados de maior poder aquisitivo teriam tanto acesso à Internet, e poderiam ser tão ou melhores informados, quanto os usuários ricos dos países desenvolvidos. Esse contexto de ambigüidade é propício a afetar ainda mais gravemente o Brasil.

Os jovens pertencentes às classes mais abastadas têm acesso ao ciberespaço, podendo usufruir das vantagens que o espaço digital pode oferecer em termos de diversificação e velocidade de informações (BARBOSA, NEVES, SANTOS, 2006). Esses benefícios ampliam suas possibilidades de comunicação, educação e inserção no mercado de trabalho, ao passo que os jovens das camadas menos favorecidas ficam privados das possíveis oportunidades da acessibilidade digital, podendo comprometer não apenas suas oportunidades no mercado de trabalho, mas seu desenvolvimento cognitivo como um todo. Observa-se uma nova interatividade para os que têm acesso às news media conforme afirma Marshall (2004, p.27, tradução nossa) "[...] há menos distição de separação das tarefas, por exemplo, entre trabalho e lazer, ou entre as compras, ou mesmo entre entretenimento e educação [...]” para os incluídos digitalmente.

Segundo Dijk (2005), pessoas com alto nível de educação utilizam aplicações nas TIC mais complexas, enquanto que pessoas com níveis mais baixo fazem consultas simples, utilizando muito mais a Internet para games e entretenimento. Pode-se observar que, nos estudos estatísticos divulgados pelo Banco Mundial (2006), as maiores densidades de acesso ao ciberespaço e de uso das tecnologias digitais coincidem com os principais centros mundiais de pesquisa científica, de atividade econômica e de movimentações financeiras. Assim, os indicadores, principalmente aqueles que se referem aos países em desenvolvimento, sustentam a expressão bíblica "the rich get richer" ou "os ricos mais ricos".

Sob essa visão, a inserção dos cidadãos na nova era da informação passa a ser uma obrigação dos poderes públicos. A oficialização da inserção do Brasil nesse novo contexto de inclusão foi o "Programa Sociedade da Informação" por meio do Decreto 3.294 de 15 de dezembro de 1999 cuja sua finalidade substantiva é:

[...] alcançar os alicerces de um projeto estratégico, de amplitude nacional, para integrar e coordenar o desenvolvimento e a utilização de serviços avançados de computação, comunicação e informação e de suas aplicações na sociedade (BRASIL, p.5, 2000).

Ainda fazem parte deste mesmo escopo de quesitos, e que mais tem a ver com o tema abordado nesse estudo, a universalização do acesso (combatendo desigualdades e promovendo a cidadania) e a educação e aprendizado ao longo da vida (desenvolvendo competência).

Enc. Bibli: R. Eletr. Bibliotecon. Ci. Inf., Florianópolis, n. 26, 2º sem.2008 
Na busca de promover a cidadania através da universalização de acesso ao espaço digital, é importante lembrar que a distribuição universal dos serviços de informação não é suficiente para a inserção dos indivíduos como cidadãos. Takahashi afirma que "no Brasil, o crescimento recente das telecomunicações tem democratizado o uso do telefone, enquanto que o acesso à rede Internet ainda é restrito a poucos” (BRASIL, 2000, p. 7). Logo se percebe a presença da exclusão digital no território brasileiro, visto que apenas a obtenção da linha telefônica não permite a conexão do usuário com o ciberespaço.

Em se tratando de educação e aprendizado, Takahashi no Livro Verde coloca a educação continuada como um fator preponderante na construção de uma Sociedade da Informação. Na mesma linha das abordagens que consideram que a exclusão digital possui outras dimensões além da técnica, mencionadas anteriormente, ele acresce que não basta a disponibilidade de uma infra-estrutura moderna de comunicação, mas sim a transformação da informação em conhecimento. Incluir o indivíduo também é proporcionar oportunidade de participação na esfera governamental de maneira efetiva, ou seja, através da utilização dos serviços públicos que os portais do governo prometem oferecer.

Lévy (1999, p.185) chama a atenção para importância da democracia eletrônica quando afirma que "uma política voluntarista da parte dos poderes públicos, de coletividades locais, de associações de cidadãos e de grupos de empresários pode colocar o ciberespaço a serviço do desenvolvimento de regiões desfavorecidas explorando ao máximo seu potencial de inteligência coletiva”. O autor também cita alguns exemplos de como explorar esse tipo de inteligência, através da valorização das competências locais, organização das complementaridades entre recursos e projetos, troca de saberes e experiências, redes de ajuda mútua, maior participação da população nas decisões políticas, abertura planetária para especialidades e parcerias.

Ao dificultar o desenvolvimento, a exclusão digital contribui para a consolidação da pobreza e distanciamento das camadas sociais, que também pode ser percebida no âmbito mercadológico, visto que as oportunidades de emprego tornam-se escassas para os digitalmente excluídos. Para que a alfabetização digital possa ser universalizada, depende da ação do Estado. Não esquecendo também, de que a formulação, execução e avaliação das políticas públicas necessitam do envolvimento das organizações não-governamentais (ONGs), organizações corporativas e da sociedade civil.

Devido à importância desse acesso, formas organizativas da sociedade civil como ONGs, movimentos sociais, sindicatos e associações de bairro podem cooperar para que os cidadãos desempenhem sua cidadania mediante a provisão de informações incluídas nos seus direitos políticos, civis e sociais conquistados ao longo do tempo. Um dos exemplos dessa cooperação é a criação de telecentros públicos de acesso.

Os telecentros são espaços com computadores conectados à Internet banda larga, geralmente gratuita. Cada unidade possui normalmente entre 10 e 20 micros - podendo não ser uma regra invariável. O uso livre dos equipamentos, cursos de informática básica e oficinas especiais são as principais atividades oferecidas à população. Cada telecentro possui um Conselho Gestor, formado por membros da comunidade e eleitos pela mesma, que ajudam os funcionários na fiscalização e gestão do espaço (MINISTÉRIO..., 2006).

O objetivo central dos telecentros é combater a exclusão digital. Trata-se de uma iniciativa fundamental de capacitação da população brasileira, visando à inserção na Sociedade da 
Informação. Além de incentivar a criação de postos de trabalho com maior qualidade para um desenvolvimento tecnológico sustentável e ambientalmente correto, aprimorando a relação entre o cidadão e o poder público na construção da cidadania digital e ativa.

No estudo sobre os projetos enquadrados sob a denominação "inclusão digital" na cidade de Salvador, Lemos e Costa (2005) propõe uma matriz para a análise desses tipos de projetos. Nela, os pesquisadores dividiram as formas de acesso, em duas categorias denominadas de inclusão digital espontânea e induzida.

Espontânea - Formas de acesso e uso das TIC em que os cidadãos estão imersos com a entrada da sociedade na era da informação, tendo ou não formação para tal uso. A simples vivência em metrópoles coloca o indivíduo em meio a novos processos e produtos em que ele terá que desenvolver capacidades de uso das TIC. Como exemplo podemos citar: uso de caixas eletrônicos de bancos, cartões de crédito com chips, smart cards, telefones celulares, etc.

Induzida - Projetos induzidos de inclusão às tecnologias eletrônicas e às redes de computadores executados por empresas privadas, instituições governamentais e/ou não governamentais. Três categorias de Inclusão Digital Induzida:

Técnica - Destreza no manuseio do computador, dos principais softwares e do acesso à Internet. Estímulo do capital técnico

Cognitiva - autonomia e independência no uso complexo das TIC. Visão crítica dos meios, estímulo dos capitais cultural, social e intelectual. Prática social transformadora e consciente. Capacidade de compreender os desafios da sociedade contemporânea

Econômica - capacidade financeira em adquirir e manter computadores e custeio para acesso à rede e softwares básicos. Reforço dos quatro capitais (técnico, social, cultural, intelectual).

Após a análise dos projetos, os pesquisadores constataram que o Tabuleiro Digital se insere na categoria técnica da variável induzida, pois existe apenas disponibilização de computadores proporcionando a indução da utilização da Internet e dos softwares disponíveis.

\section{4 \\ ASPECTOS DE INCLUSÃO DIGITAL: O CASO DO TABULEIRO DIGITAL}

Conforme visto anteriormente, a inclusão digital é mais do que ter acesso às máquinas. É o exercício da cidadania na interação com o mundo da informação e da comunicação. $O$ Tabuleiro Digital é uma iniciativa da Faculdade de Educação da Universidade Federal da Bahia - FACED-UFBA pela inclusão digital dos estudantes e da comunidade não-acadêmica. O projeto é fruto de uma parceria entre a UFBA, a Fundação ADM e a Petrobrás, com apoio do Liceu de Artes e Ofícios e do Projeto Software Livre da Bahia. Segundo seu idealizador, Nelson Pretto $^{2}$ (então diretor da FACED-UFBA) o objetivo principal do projeto era tornar o

\footnotetext{
${ }^{2}$ Site do Tabuleiro Digital da Faculdade de Educação da UFBA. < $\underline{\text { http://twiki.dcc.ufba.br/bin/view/Tabuleiro/ProjetoTabuleiro }}$ Digital>.

Enc. Bibli: R. Eletr. Bibliotecon. Ci. Inf., Florianópolis, n. 26, 2ºm.2008
} 
uso da rede tão cotidiano e simples quanto comer um acarajé (quitute da culinária baiana afro e muito popular, a ponto de ser, comercializado em todas as esquinas da capital, Salvador).

O Tabuleiro Digital está estruturado nas áreas de circulação dos três andares da Faculdade, reunindo 20 computadores, rodando software livre. As máquinas estão sobre suportes que lembram os tabuleiros das baianas. São de madeira, compensado, e têm os apoios em forma de " $X$ " acompanhados de um pequeno banco sem encosto. Essa estrutura foi projetada, pensando em criar um ambiente versátil, onde as pessoas pudessem utilizar a Internet sem ficarem limitadas às salas de laboratórios de informática da própria Universidade.

Por ser um espaço público de socialização, totalmente desvinculado de salas de aula ou de qualquer disciplina, uma característica marcante de sua funcionalidade é a não "pedagogização" do uso da Internet (ou seja, sem a orientação sistemática sobre a utilização da Internet e programas disponíveis). Essa característica difere dos demais laboratórios de informática presentes em todas as unidades da Universidade.

Segundo o professor Nelson Pretto, em entrevista, "[...] o Tabuleiro é um ponto de encontro para quem quiser usar a Internet, para o fim que desejar. Não tem qualquer controle ou supervisão por parte de professores ou funcionários da instituição". No entanto, um dos aspectos determinante da universalização de acesso condicionado ao letramento digital, ou até mesmo à alfabetização digital, é que o acesso à rede exige dos usuários alguma capacitação em informática.

Aproveitando o estudo realizado por Lemos e Costa (2005), foram levantadas as prospecções para a análise empírica a partir do perfil do usuário do Tabuleiro Digital (idade, escolaridade, ocupação e renda familiar) e alguns cruzamentos de variáveis qualitativas que explicam os aspectos desse tipo de inclusão. Também foram realizadas algumas ligações com as definições de inclusão digital na visão de Takahashi (apud BRASIL, 2000), Soares (2002), Rondelli (2003), Sorj (2003), Dijk (2005) e Warschauer (2006).

\subsection{RECORTE METODOLÓGICO DA PESQUISA}

A pesquisa se caracterizou como um estudo de caso, com a realização de levantamento sobre o Tabuleiro Digital da FACED/UFBA, que tem como usuários potenciais os habitantes da Cidade de Salvador no Estado da Bahia (Brasil). A amostra foi composta por 75 (setenta e cinco) usuários deste telecentro, selecionada pelo critério da acessibilidade, entretanto, este foi adotado apenas entre aqueles usuários que já haviam freqüentado o Tabuleiro pelo menos três vezes. Também integraram a amostra duas pessoas envolvidas com o projeto, sendo um docente e um prestador de serviços da FACED que, eventualmente, atende as demandas dos usuários.

Para a coleta de dados foram utilizadas as técnicas da observação direta, aplicação de questionários e realização de entrevistas. As entrevistas foram realizadas com o docente e o prestador de serviços, já os questionários foram aplicados junto aos usuários que freqüentaram os três turnos que compreendem o horário de funcionamento do telecentro. As atividades desenvolvidas por eles no Tabuleiro foram observadas diretamente pelas as pesquisadoras no mesmo período.

Quanto aos instrumentos, registra-se que o questionário foi composto de questões abertas e fechadas, buscando-se obter informações sobre o perfil dos usuários, sobre a utilização que 
estes fazem do telecentro e sobre suas demandas para esse espaço de acesso à Internet. No diário de campo procedeu-se o registro cursivo das informações levantadas durante o desenvolvimento das atividades no telecentro. Também foi realizada uma análise do próprio site do Tabuleiro. O tratamento estatístico dos dados foi efetuado por meio do software Sphinx, com análise desenvolvida a partir da integração das abordagens quantitativa e qualitativa.

\subsection{APRESENTAÇÃO E DISCUSSÃO DOS RESULTADOS}

O exame dos dados indicando a freqüência no Tabuleiro apresenta que os jovens de 17-21 (33,3\%), em sua maioria estudantes, são os maiores usuários. Também foi possível perceber uma alta freqüência para a faixa etária de 12-16 anos (28,0\%) e 22-26 anos (24,0\%). De 27-31 $(6,7 \%)$ e na amostra de mais de 32 anos $(3,0 \%)$ se enquadra um morador de rua que é usuário assíduo do telecentro.

Em seu estudo sobre os telecentros comunitários, em particular, a experiência do sampa.org ${ }^{3}$, Assumpção (2003, p. 194) descreve algumas características do perfil desses usuários. O autor afirma que "[...] 70\% destes é do sexo feminino, na faixa etária de 13 a 17 anos (60\%)" em concordância com os dados desse estudo. Entretanto, diferente dos dados apontados por Assumpção (2003, p.195), onde “[...] existem usuários acima de 60 anos e abaixo dos 12 anos de idade, que são minoria, mas freqüentam os pontos (3\%) [...]”, essa pesquisa não verificou nenhum usuário no telecentro com mais de 35 anos.

Interessante que, a respeito da localização do telecentro - dentro dos limites de uma faculdade situada afastada de residências e da rota de passagem do grande público - observou-se uma freqüência regular de estudantes de nível médio "fardados com camisas” de escola pública.

Pôde-se observar também a presença de estudantes de nível superior incompleto (38,7\%), porém dentre os que freqüentam "mais de uma vez por semana" (36,0\%) e "todos os dias" $(14,7 \%)$ estão como maiores freqüentadores os que possuem grau médio incompleto (17) ocorrências, seguido do nível superior (14). Dos usuários do Tabuleiro Digital que estão cursando o nível superior, 54\% são alunos da FACED. Por serem estudantes desta instituição, além da opção de utilizarem o telecentro, eles também têm acesso aos laboratórios de informática. Os estudantes de outras instituições de ensino representam 45,16\% do total de respondentes que estão cursando o nível superior, verificou-se também que grande parte destes são estudantes da Universidade, prevalecendo os estudantes do Instituto de Letras, localizado no Campus de Ondina. No período em que foi realizada a pesquisa, observou-se um conflito $^{4}$, sem nenhum tipo de mediação, existente entre grupos de pessoas da comunidade, estudantes de outras escolas e os estudantes da própria FACED.

Quando questionados sobre o principal impacto da Internet em suas vidas o fator "Relações Sociais” foi o mais indicado na faixa etária que compreende 12 a 26 anos - público que também é o mais freqüente (89,3\%). O fator educação foi a segunda opção mais designada

\footnotetext{
${ }^{3}$ Projeto liderado pelo Instituto de Políticas Públicas Florestan Fernandes - IFF, unindo empresas, entidades da sociedade civil, sindicais e Instituições de ensino e pesquisa. No dia 13 de Julho de 2000, o Projeto iniciou suas atividades com a abertura de seis Telecentros comunitários. Dois meses depois abriu mais quatro, funcionando com dez computadores cada.

${ }^{4} \mathrm{O}$ conflito, com relação à utilização das maquinas, era muito mais referente ao conteúdo acessado e tempo de utilização.

Enc. Bibli: R. Eletr. Bibliotecon. Ci. Inf., Florianópolis, n. 26, 2ºm.2008
} 
pelos que tem idade entre 12 e 26 como se confere no Quadro 1. As páginas de Governo Eletrônico (GE) e empregabilidade apresentaram poucas indicações pelos usuários. Esses dados concordam com as pesquisas desenvolvidas pelo NIC.br, indicando que no Brasil, as maiores proporções de indivíduos que usam a Internet para educação estão na "classe A (85\%) e classe B (73\%)” (COMITÊ..., 2007).

\begin{tabular}{|l|c|c|c|c|c|}
\hline Idade x Impacto & Empregabilidade & Educação & $\begin{array}{c}\text { Relações } \\
\text { Sociais }\end{array}$ & $\begin{array}{c}\text { Facilidade nos serviços de } \\
\text { utilidade publica }\end{array}$ & Total \\
\hline $12-16$ & 1 & 7 & 12 & 1 & 21 \\
\hline $17-21$ & 4 & 7 & 11 & 3 & 25 \\
\hline $22-26$ & 0 & 8 & 9 & 4 & 21 \\
\hline $27-31$ & 1 & 4 & 0 & 0 & 5 \\
\hline $32-m a i s$ & 0 & 1 & 1 & 0 & 2 \\
\hline Total & $\mathbf{6}$ & $\mathbf{2 7}$ & $\mathbf{3 3}$ & $\mathbf{8}$ & $\mathbf{7 5}$ \\
\hline
\end{tabular}

Quadro 1 - Impacto da Internet na vida dos usuários

* O valor corresponde a soma de uma observação sem resposta ao total em linha e em coluna.

Pôde-se observar que para os freqüentadores do Tabuleiro, a Internet é um meio de comunicação mais rápido e que funciona como encurtador de distâncias enquanto meio fomentador das relações sociais. Muitos adicionaram às suas respostas, que as ferramentas que promovem as redes sociais on-line facilitam a comunicação que incluem parentes, amigos e outros conhecidos que vivem alhures, sendo mais barato comunicarem desta maneira do que por telefone, por exemplo. Assim, é o caso de comunidades como Orkut $<$ www.orkut.com.br>, muito utilizado nesse telecentro (Tabela 1).

Tabela 1 - Uso do Orkut

\begin{tabular}{lcc}
\hline \multicolumn{1}{c}{ Importância do ORKUT } & Freqüência & Percentual (\%) \\
\hline Fortalecer laços de amizade & 60 & 80,0 \\
Meio profissional & 5 & 13,3 \\
Sem resposta & 10 & 6,7 \\
Total & 75 & 100 \\
\hline
\end{tabular}

Notou-se que, em média, oito de cada nove usuários dos quiosques do telecentro está conectado ao Orkut, acessando como tarefa principal ou minimizado, enquanto executa uma outra ferramenta de comunicação on-line como MSN ou e-mail. Dijk (2005), em The Deepening Divide, ressalta que essas aplicações da Internet variam de acordo com o nível educacional: entretenimento (educação baixa $72 \%$ e educação alta $35 \%$ ) e para à busca de informação (nível educacional baixo 53\% e alto 64\%). A exclusão parece mais estrutural quando alguns segmentos da população, sistematicamente e permanentemente, utilizam dos benefícios das aplicações da Internet e computadores mais avançados para informação, comunicação, trabalho, negócios e educação. Enquanto pessoas com nível social mais baixo, quando, utilizam esses recursos é somente para informação e comunicação simples e básica, compras e entretenimento.

Contudo chamou a atenção à utilização desta ferramenta por um usuário que se denominou músico, morador de rua e que a utiliza como meio de comunicação profissional entre seus pares, músicos. 
Segundo Warschauer (2006) a obtenção de letramento e o acesso a TIC proporcionam habilidade para o indivíduo processar e utilizar a informação, que só é possível através da conectividade, um viés essencial para promoção da inclusão digital.

\begin{tabular}{|l|r|r|r|r|}
\hline $\begin{array}{c}\text { Telefone casa } \\
\text { Renda }\end{array}$ & Sim & Não & \multicolumn{1}{c|}{$\begin{array}{c}\text { Sem } \\
\text { resposta }\end{array}$} & \multicolumn{1}{c|}{ Total } \\
\hline Até um SM & 7 & 2 & 0 & 9 \\
\hline $1-2$ SM & 14 & 5 & 0 & 19 \\
\hline $2-3$ SM & 12 & 3 & 1 & 16 \\
\hline 3-5 SM & 19 & 0 & 0 & 19 \\
\hline 5-10 SM & 7 & 1 & 0 & 8 \\
\hline 10-20 SM & 1 & 1 & 0 & 2 \\
\hline Mais de 20 SM & 1 & 0 & 0 & 1 \\
\hline Sem resposta & 0 & 0 & 1 & 1 \\
\hline TOTAL & 61 & 12 & 2 & 75 \\
\hline
\end{tabular}

Quadro 2 - Incidência de linhas telefônicas

\begin{tabular}{|l|r|r|r|r|}
\hline $\begin{array}{c}\text { PC em casa } \\
\text { Renda }\end{array}$ & \multicolumn{1}{c|}{ Sim } & \multicolumn{1}{c|}{ Não } & $\begin{array}{c}\text { Sem } \\
\text { resposta }\end{array}$ & Total \\
\hline Até um SM & 1 & 8 & 0 & 9 \\
\hline 1-2 SM & 5 & 14 & 0 & 19 \\
\hline 2-3 SM & 5 & 11 & 0 & 16 \\
\hline 3-5 SM & 8 & 11 & 0 & 19 \\
\hline 5-10 SM & 5 & 3 & 0 & 8 \\
\hline 10-20 SM & 2 & 0 & 0 & 2 \\
\hline Mais de 20 SM & 1 & 0 & 0 & 1 \\
\hline Sem resposta & 0 & 0 & 1 & 1 \\
\hline TOTAL & 27 & 47 & 1 & 75 \\
\hline
\end{tabular}

Quadro 3 - Incidência de computadores nos lares

Embora os quadros 2 e 3 apresentem pouca incidência nos entrevistados com mais de cinco salários mínimos (SM), deve-se levar em consideração, outro dado que é revelado quanto à necessidade de conexão, a partir de centros de acesso livre, por parte da população com renda familiar inferior a cinco (SM). Porém, entre os que possuem (61) e os que não possuem (12) telefone em casa, verificou-se que (47) não tem computadores em suas residências, fazendo do telecentro uma das formas de manter contato com, pelo menos, os "recursos físicos" que promovem a inclusão digital. Dados do COMITÊ... (2007) apontam que no Nordeste 86\%, do universo de 12.917 domicílios, não possuem computadores em casa devido ao alto custo. O aumento da procura dos telecentros por variados segmentos da população tem aumentado gradualmente, concordando com a premissa de Dijk (2005, p.198, tradução nossa) que “[...] mais segmentos da população estão convencidos que podem participar da sociedade da informação e ter acesso aos computadores e redes.”

O acesso físico à Internet e computadores, sem a aplicação correta do conteúdo, não funcionam como ferramentas facilitadoras para uma inclusão social plena do individuo (WARSCHAUER, 2006; SOARES,2002). Disponibilizar formas de acesso, a exemplo desses usuários “incluídos” pelo Tabuleiro Digital, já é um resultado no mínimo estimulante para se agregar alternativas que visem associar a disponibilização de TIC e conectividade juntamente com incitação de habilidades que promovam a produção do conhecimento nesses telecentros.

Em relação à utilização das ferramentas disponíveis nos computadores do Tabuleiro Digital, $73 \%$ dos entrevistados afirmaram que utilizavam o telecentro apenas para acesso à Internet, enquanto que $25 \%$ dos usuários, além de acessar a Internet, faziam uso dos softwares disponíveis nas máquinas (editores de textos, planilhas de cálculo, documentos de apresentação e outros). Alguns dos motivos apontados, pelos quais os usuários do Tabuleiro optem apenas pelo acesso à Internet, foram que as dúvidas existentes e dificuldades no uso dos recursos estão atrelados à ausência de mediadores humanos e de um treinamento para o uso dos programas em Software Livre. É perceptível a necessidade de mediadores (monitores, tutores) para fornecer as orientações na utilização das ferramentas disponíveis nas máquinas, aumentado assim os escopos de opções para os usuários.

A variável utilização reitera a necessidade de que sejam realizados novos estudos sobre este telecentro, já que sua proposta não é nem atender a comunidade acadêmica - mesmo estando dentro de uma Faculdade - nem de atender a comunidade local, por ser de difícil acesso. A 
divulgação é feita entre os usuários através do “boca a boca”, mas os entrevistados não manifestaram nenhum interesse em atrair novas pessoas para o telecentro.

O Quadro 4 apresenta as ferramentas on line e/ou quais os tipos de sites são mais utilizados pelos usuários do Tabuleiro (questão de múltipla escolha). Conforme visto em análises anteriores, existe uma predominância no número de usuários adolescentes e jovens. Nesta tabela observa-se um grande número de citações para o acesso ao Orkut (54) e programas de mensagens instantâneas (49), lembrando que estes tipos de ferramentas - principalmente o Orkut - têm sido as preferidas dos usuários mais jovens ${ }^{5}$. Mesmo sendo um telecentro, instalado em uma Instituição de ensino superior, dos 75 entrevistados apenas sete afirmaram acessar sites com informações científicas, vale ressaltar também que $41,3 \%$ do total dos entrevistados estão cursando o nível superior. Essa constatação não permite dizer que esses estudantes não buscam informações científicas em outros locais de acesso (como nos laboratórios das Instituições de ensino superior), mas seu acesso no Tabuleiro poderia ser algo oportuno e de estímulo a outros usuários na geração desse tipo de conhecimento. Alguns sites, de fomento à pesquisa, a exemplo do Portal de Periódicos da CAPES, somente podem ser acessados nos domínios da universidade pública.

\begin{tabular}{|l|c|}
\hline \multicolumn{1}{|c|}{ Uso da Internet } & Quant. Citações \\
\hline Programas de mensagens instantâneas (MSN, ICQ e outros) & 49 \\
\hline Chats (Bate papo) & 3 \\
\hline Orkut & 54 \\
\hline Correio eletrônico (e-mail) & 39 \\
\hline Home Page & 8 \\
\hline Sites de busca & 25 \\
\hline Biblioteca da UFBA (on line) & 6 \\
\hline Informações Científicas (periódicos, banco de teses/dissertações) & 7 \\
\hline Sem resposta & 1 \\
\hline
\end{tabular}

Ainda em relação à preferência dos jovens foi revelado que dentre as opções de finalidade no uso da Internet o entretenimento foi a mais indicada (51) vezes. A opção por realizar trabalho escolar foi a segunda mais indicada (39), ou seja, 52\% dos usuários do Tabuleiro encontraram neste telecentro a oportunidade de garantir suas atividades escolares, mesmo sentindo algumas dificuldades na utilização dos softwares disponíveis (editores de textos e planilhas de cálculo) em Software Livre. Realizar pesquisas acadêmicas (28) e buscar informações específicas (religião, política, “tribos”) apontadas por (22) observações, além de (21) citações para mídias eletrônicas (jornais, revistas, etc) leva a acreditar que se houvesse orientação o Telecentro poderia estimular o lado educativo, podendo passar para categoria cognitiva. Vislumbra-se tal perspectiva, principalmente, por se tratar de uma iniciativa que atende na grande maioria estudantes $(89,3 \%)$, cursando do nível fundamental incompleto ao superior incompleto, entre 12 e 26 anos e por ser instalado dentro da Faculdade de Educação.

\footnotetext{
${ }^{5}$ Brazilian Internet Steering Committee. Survey on the Use of Information and Communication Technologies in Brazil ICT HOUSEHOLDS and ICT ENTERPRISES 2007. São Paulo, 2008. Disponível em: $<$ http://www.cetic.br/tic/2007/indicadores-cgibr-2007.pdf $>$. Acesso em: ago. de 2008. Ver também: Lacerda (2005); Folha Online (jul, 2008) e Cetic (2006).

Enc. Bibli: R. Eletr. Bibliotecon. Ci. Inf., Florianópolis, n. 26, $2^{\circ}$ sem.2008
} 
Dentre as opções menos indicadas estão esportes (17), busca de emprego (13) e governo eletrônico com (5) citações. Esses dados chamaram à atenção que, neste telecentro, os usuários procuram a Internet, muito mais com a finalidade de atividades ligadas à interação e ao entretenimento.

Com relação às habilidades de uso da Internet, a pesquisa verificou que a maioria dos respondentes (no total de 44) possui a capacidade de baixar arquivos e instalar programas; 41 responderam que são capazes de entrar numa sala de bate-papo; 26 estão aptos para entrar em uma lista de discussão e 22 conseguem fazer o (re)cadastramento em sites. Se relacionarmos estes resultados com o perfil da maioria jovem e de baixa renda dos respondentes, talvez seja possível produzir uma análise adicional sobre os hábitos de uso da Internet entre diferentes grupos sócio-demográficos. Por exemplo, somente 15 respondentes disseram ser capazes de fazer compras pela Internet, 12 constroem blogs, (nove) disseram que conseguem instalar programas advindos da rede e outros (cinco) disseram saber realizar transações bancárias. Ora, se a maioria dos sites que permitem a efetuação de compras e de transações bancárias pela rede é intuitiva, talvez seja possível inferir que estas habilidades não foram desenvolvidas em função de condições sócio-econômicas específicas. Não sendo uma falta de habilidade em função da dificuldade de se executar tais tarefas.

Assim, levando em consideração a análise dos dados e as classificações de Lemos e Costa (2005), pode-se confirmar, pelas características do projeto e pelo perfil da grande maioria dos usuários, que o tipo de inclusão induzida na perspectiva técnica é o mais percebido no telecentro da FACED. A premissa versa que o processo de “inclusão" deve ser visto sob os indicadores técnicos, econômicos e cognitivos, visando à ampliação dos capitais técnico, cultural, social e intelectual. No entanto, para aquele tipo de usuário que tem certa habilidade no uso dos meios digitais, autonomia e independência no uso complexo das TIC, além de possuir uma visão crítica destes meios, passaria para o nível de inclusão induzida cognitiva contribuindo para o aumento dos quatro capitais citados.

Para os autores que vêm refletindo a educação e o aprendizado - a exemplo de Warschauer e Soares - como algo preponderante na construção de uma Sociedade da Informação, não bastaria o telecentro disponibilizar uma infra-estrutura moderna de comunicação, mas sim a transformação da informação em conhecimento.

Segundo a visão de Sorj (2003) dos cinco níveis interdependentes da inclusão digital, o projeto Tabuleiro Digital atenderia apenas aos dois primeiros níveis, infra-estrutura de comunicação e equipamentos, deixando de oferecer os três níveis restantes, que seriam o treinamento, a capacitação intelectual do usuário e o estímulo à produção de conteúdo.

A visão de Rondelli (2003) não diverge da visão de Takahashi discutida no Livro Verde em 2000. De acordo com os passos de inclusão definidos pela autora, o Tabuleiro Digital teria dado o primeiro passo (a oferta de computadores conectados em rede) para a inclusão digital. Porém, para incluir digitalmente o processo é mais complexo, pois não basta favorecer, somente, o acesso aos meios digitais.

E para concluir este processo, vislumbra-se que sejam criadas oportunidades para que os aprendizados feitos a partir dos suportes técnicos e digitais possam ser empregados no cotidiano da vida e do trabalho. Ou seja, o processo engloba desde a indução de maneira educativa (onde a aprendizagem tem papel fundamental) até a exploração máxima dos meios digitais na atual era da informação.

Enc. Bibli: R. Eletr. Bibliotecon. Ci. Inf., Florianópolis, n. 26, 2ºm.2008 
Os aspectos de inclusão digital observados no Tabuleiro Digital levantaram uma série de questionamentos, a exemplo de: como confiar na divulgação eficaz do telecentro se os entrevistados manifestaram pouco interesse em atrair novos usuários? Como se promove inclusão digital efetiva nestas circunstâncias? ${ }^{6}$ A mediação humana em telecentros é um recurso essencial à inclusão digital que visa desenvolver inclusão social. Se os coordenadores de projetos, como o aqui ora apresentado, perceberem a necessidade de mediadores, seria um indício de estímulo à alfabetização digital? Um prenúncio a importância da mediação humana para o letramento digital?

\section{CONSIDERAÇÕES FINAIS}

Diante dos aspectos inerentes à inclusão digital na Sociedade da Informação, percebe-se que a inclusão vai além de um acesso físico aos recursos técnicos, ou seja, computador e Internet. É preciso criar condições para fomentar um uso crítico, livre e inventivo em relação às novas tecnologias de informação e comunicação.

Após o estudo empírico que revelou o perfil dos usuários do telecentro observado e as variáveis intrínsecas aos aspectos de inclusão digital, ficou evidenciado que segundo as características do projeto é pertinente classifica-lo como inclusão digital na categoria induzida (técnica). Também se constatou a solicitação por parte dos usuários de orientação para utilização dos recursos - tanto dos softwares como da Internet - assim como a regulação do período de acesso. Tais solicitações colocam em questão a aplicabilidade do telecentro, se levarmos em consideração que os usuários anseiam pela oferta de recursos além dos que são atualmente disponibilizados.

Solicitar alguém que oriente na navegação de páginas e na utilização de aplicativos do Software Livre indica que este telecentro poderia potencializar acesso às ferramentas técnicas e ao conteúdo da Internet em seu público - formado, na sua maioria, por estudantes de escolas públicas e moradores de rua - à fim de quiçá desenvolver o lado cognitivo.

A ausência de um responsável direto pelo controle da utilização dos recursos oferecidos limitou o fornecimento de informações como a quantidade média de usuários, a freqüência diária e freqüência de horário dos usuários nas máquinas (o que também pode ser considerado como um fator limitador da pesquisa). Também foi percebido que a ausência de monitores (Recurso Humano) neste telecentro se constituía uma brecha para conflitos entre os usuários internos (estudantes da FACED) e usuários externos, além da ausência de segurança no local e um controle das páginas visitadas. Tanto a falta de um treinamento no uso dos recursos quanto a ausência de controle do conteúdo acessado podem ser sugeridos como causas para que, dentre as opções de finalidade no uso da Internet, o entretenimento tenha sido a mais indicada. Assim, sugeri-se a realização de estudos adicionais, investigando essa questão.

A diminuição de computadores em funcionamento também constituiu uma limitação somente nove dos 20 PCs propostos no projeto estavam em funcionamento, situação que resultou no aumento de dias dedicados à coleta de dados para esta pesquisa.

A inclusão digital pode ser considerada à apropriação dos meios digitais. Uma apropriação plena, entretanto, exige mais do que o simples uso técnico das ferramentas, outras habilidades,

\footnotetext{
${ }^{6}$ Essas questões foram incitadas no decorrer do tratamento dos dados, fator que estimula a continuidade do estudo nesses projetos.

Enc. Bibli: R. Eletr. Bibliotecon. Ci. Inf., Florianópolis, n. 26, $2^{\circ}$ sem.2008
} 
como a capacidade de transformar a informação em conhecimento e de produzir conteúdo precisam ser desenvolvidas. Sendo assim, um ambiente que propõe a promover uma inclusão digital plena de seus usuários precisa oferecer condições favoráveis ao desenvolvimento dessas habilidades adicionais.

Um telecentro é considerado um espaço capaz de combater com eficácia a exclusão quando este reúne em seu projeto: conectividade, tecnologia da informação e da comunicação, além de recursos humanos que relacionados de maneira interativa e efetiva tornam-se capazes de gerar o conhecimento, valorizado na sociedade atual. Tais recursos não foram constatados por este estudo no Tabuleiro Digital.

Percebe-se a importância de se criar nessas iniciativas uma estratégia que abarque os recursos necessários que favorecem o acesso a conteúdos que transformam o lado cognitivo de seus usuários. A convergência dos recursos físico, digital, social e humano pode favorecer que o aspecto de inclusão digital percebido neste telecentro passe da categoria técnica à cognitiva. Tal procedimento colocaria esta iniciativa como parte de um círculo da alta inclusão digital que pode gerar inclusão social e consequentemente, maior desenvolvimento. Pois é através do acesso às fontes de informação adequadas, que o indivíduo pode transformar esse insumo em conhecimento e, mais tarde, explicita-lo como informação acrescida de relevância para o desenvolvimento do lado sócio-econômico.

\section{REFERÊNCIAS}

AFONSO, C. A. Internet no Brasil: o acesso para todos é possível. São Paulo: Frietrch Ebert, 2000.

ASSUMPÇÃO, R. Telecentros comunitários: peça chave da inclusão digital - a experiência do sampa.org. In: S. A. da e CASSINO, J. (Org.) Software livre e inclusão digital. São Paulo: Conrad Editora do Brasil, 2003. 339p.

BANCO MUNDIAL Relatório do desenvolvimento humano 2006: poder, pobreza e a crise mundial da água. BM: Brasil, 2006.

BARBOSA; A.; NEVES, B. C.; SANTOS; J.C.S. Aspectos de inclusão digital: perfil dos usuários do telecentro da FACED-UFBA. In: COLÓQUIO INTERNACIONAL SOBRE PODER LOCAL, 10., 2006, Salvador. Anais... Salvador: Centro Interdisciplinar de Desenvolvimento e Gestão Social, 2006. CD-ROM.

BRASIL. Ministério da Ciência e Tecnologia. Conselho Nacional de Ciência e Tecnologia. Sociedade da informação no Brasil: livro verde. Brasília, 2000. 203p.

BONILLA, M.H. O Brasil e a alfabetização digital. Jornal da Ciência, Rio de Janeiro, 13 de abril de 2001.

CASTELLS, M. A sociedade em rede. Vol.1, 5 ed. São Paulo: Paz e Terra, 1999. 617p.

COMITÊ GESTOR DA INTERNET NO BRASIL. CETIC.br. Set.-nov., 2007. Disponível em: <http://www.cetic.br/usuarios/tic/2007/index.htm>. Acesso em: 17 ago. 2008.

CONSELHO NACIONAL DE CIÊNCIA E TECNOLOGIA (Brasil). Sociedade da

informação: ciência e tecnologia para a construção da Sociedade da Informação no Brasil. Brasília, 1998. 164p.

EISENBERG, J.; CEPIK, M. Internet e política. Belo Horizonte: Humanitas, 2002.

HOBSBAWN, E. A era dos extremos: o breve século XX: 1914-1991. 2ed. São Paulo: Companhia das Letras, 2005, 598p. 
LEMOS, A.; COSTA, L. F. Um modelo de inclusão digital: o caso da cidade de Salvador. Revista de Economía Política de las Tecnologías de la Información y Comunicación. <www.eptic.com.br>, v. 8, n. 6, Sep./Dic. 2005.

LÉVY, P. Cibercultura. São Paulo: Editora 34, 1999. 260p.

MARSHALL, P. D. New media cultures. New York: Arnold, 2004

MAYNARD, H. B.; MEHRTENS, S. E. A quarta onda. São Paulo, Cultrix, 1999.

MATTELART, Armand. História da Sociedade da Informação. 2ed. São Paulo: Edições Loyola, 2002. 197p.

MINISTÉRIO DAS COMUNICAÇÕES - MC. 2006. Disponível em: $<$ http://www.idbrasil.gov.br>. Acesso em: 15 jul. 2006.

RODA VIVA (Programa Televisivo), 2000, São Paulo. Entrevista com o sociólogo Manuel Castells sobre o vol. I da trilogia a sociedade em rede. Disponível em DVD e VHS e acesso em 14 de julho de 2006.

RONDELLI, E. Quatro passos para a inclusão digital. Disponível em: $<$ http://www.comunicacao.pro.br/setepontos/5/4passos.html>. Acesso em: 20 ago. 2006.

SANTOS, Milton. Por uma outra globalização: do pensamento único à consciência universal. Rio de Janeiro: Record, 2004.

SILVEIRA, S.A. da. Exclusão digital: a miséria na era da informação. São Paulo: Fundação Perseu Abramo, 2005. 47p.

SILVEIRA, S.A. da; CASSINO, J. Inclusão Digital, Software Livre e Globalização ContraHegemônica. In: S. A. da e CASSINO, J. (Org.) Software livre e inclusão digital. São Paulo: Conrad Editora do Brasil, 2003. 339p.

SOARES, M. Novas práticas de leitura e escrita: letramento na cibercultura. Educ. Soc., Campinas, vol. 23, n. 81, p. 143-160, dez. 2002. Disponível em $<$ http://www.cedes.unicamp.br $>$. Acesso em: 15 ago. 2008.

SORJ, B. Brasil@povo.com.: a luta contra a desigualdade na sociedade da informação. Rio de Janeiro. Jorge Zahar, 2003.

STAROBINAS, L. Repensando a exclusão digital. 2006 Disponível em: $<$ http://www.cidade.usp.br/arquivo/artigos/index0902.php>. Acesso em 12 jul. de 2006.

FACED-UFBA. Tabuleiro Digital. 06 de dezembro de 2004. Disponível em $<$ http://twiki.im.ufba.br/bin/view/Tabuleiro/OsInfoincluidos> . Acesso em: 28 jun. 2006.

TOFFLER, A; TOFFLER, H. Criando uma nova civilização: a política da terceira onda. 5 ed. Rio de Janeiro: Record, 1997. 142p.

Tunis Commitment, World Summit on the Information Society, Tunes, 18 de Novembro de 2005. Disponível em: <http://www.itu.int/dms_pub/itu-s/md/03/wsis/doc/S03-WSIS-DOC0005!!PDF-E.pdf >. Acesso em: 13 de ago. 2008.

WARSCHAUER, M. Tecnologia e inclusão social: a exclusão digital em debate. São Paulo: Senac, 2006. 319p.

\section{ABSTRACT}

This article brings results of a case study applied with survey, seeking to analyze the aspects of the digital inclusion through the users of Tabuleiro Digital public Internet access point of the College of Education of the Federal University of Bahia - FACED/ UFBA. The main objective study was intended to investigate the type of digital inclusion, promoted by this Project, in accordance with perspective of the literature present. The specific objectives indicate the characteristics of the profile from the users; types of applications used and purpose of the Internet confrontation with levels of education and social. In this way, the information society and digital inclusion are contextualized; also the aspects of the inclusion 
of the Tabuleiro are demonstrated and discussed. Finally, with the analysis, was evidenced that the type of digital inclusion of the Project is induced (technique).

KEYWORKS: Information society. Digital inclusion. Public Internet access point.

Originais recebidos em: 19/06/2008

Texto aprovado em: 02/09/2008 